\title{
As vertentes das águas minerais: um conflito ambiental em Caxambu, MG
}

\section{Multiple roles of mineral water: an environmental conflict in Caxambu, MG}

João Pedro Moreira Costa - Graduando em Serviço Social, pela Universidade Vale do Rio Verde de Três Corações (UninCor). E-mail: joaopedromoreiracosta@yahoo.com.br.

Maria Alice Fernandes Corrêa Mendonça - Doutora em Desenvolvimento Rural, pela Universidade Federal do Rio Grande do Sul (UFRGS) com período sanduíche no Rural Sociology Group (Wageningen University), The Netherlands. Professora efetiva no Departamento de Economia Rural da Universidade Federal de Viçosa (DER/UFV). E-mail: maria.alice.fcm@gmail.com.

Lucas Magno - Doutor em Geografia, pela Universidade Federal de Santa Catarina (UFSC). Professor no Instituto Federal de Educação, Ciência e Tecnologia do Sudeste de Minas Gerais (IF SUDESTE MG).E-mail: lucas.magno@ifsudestemg.edu.br.

\section{Resumo}

$\mathrm{O}$ artigo versa sobre o conflito ambiental em torno das águas minerais em Caxambu, Minas Gerais. Discute-se a contingência dos diferentes significados culturais, políticos, sociais e econômicos das águas e como isso provocaria disputas entre população, setores públicos e empresas privadas. $\mathrm{O}$ artigo resultou de pesquisa bibliográfica e pesquisa de campo em Caxambu, referentes a observação participante em fóruns, audiências e manifestações públicas. Compreendeu-se que alterações na interpretação do Código das Águas Minerais, orientadas pelo Código da Mineração, permitiram a classificação de praticamente todo tipo de água subterrânea potável como água mineral, contribuindo para potencializar o conflito. A maior visibilidade ao conflito, logo, se deu a partir do processo de privatização da exploração econômica das águas minerais. Finalmente, identificaramse as vertentes das águas referentes aos seus diferentes significados territoriais, quais sejam: água como saúde e direito e água como recurso econômico.

\section{Palavras-chave}

Águas Minerais. Conflito Ambiental. Código da Mineração. Privatização.

\begin{abstract}
This paper brings up the environmental conflict around the mineral water in Caxambu, Minas Gerais. The contingency of the different cultural, political, social and economic meanings of the waters is discussed and how this would provoke disputes between population, public sectors and private companies. The paper results from bibliographic research and data collected during field work at the locality. These data were based on participant observation at forums and manifestations. The broader comprehension is that changes in interpretation of the Mineral Water Code, oriented by the Mineration Code, allowed almost all type of subterranean water to be classified as mineral water, which contributed in large measure to reinforce the conflict. The major visibility to the conflict, thus, occurred since the privatization of economic water exploration. Finally, different interpretive approaches of water are identified, related to its different territorial meanings, water ashealth and right, and water as economic resource.
\end{abstract}

\section{Keywords}

Mineral Water. Environmental Conflict. Mineration Code. Privatization. 


\section{INTRODUÇÃO}

O município de Caxambu, localizado ao sul do estado de Minas Gerais e pertencente ao Circuito das Águas, é conhecido como uma estância hidromineral devido a existência de águas minerais e termais em seu território. Desde o início de 1980, contudo, Caxambu também tem sido reconhecida por conta da exploração comercial de suas águas por empresas privadas, por meio do envasamento das águas potáveis de mesa e gasosas. A exploração com fins comerciais tem levantado preocupação na população, uma vez que as águas minerais, para além do significado econômico, têm valor cultural e terapêutico, e seu acesso é considerado um direito humano básico.

Nesse contexto, este artigo propõe uma discussão sobre os diferentes usos das águas minerais em Caxambu que têm ocasionado um conflito ambiental (ACSELRAD, 2004). Trabalha-se com a contingência de diferentes significados culturais, políticos, sociais e econômicos das águas minerais nesse município, o que provocaria disputas entre população, setores públicos e empresas privadas. Identificaram-se duas vertentes das águas referentes aos seus diferentes significados territoriais: i) água como saúde e direito humano básico; e ii) água como mercadoria.

Argumenta-se que o que está em jogo no conflito ambiental nesse município é, por um lado, uma tendência privatista das águas minerais encampada, principalmente, por empresas privadas e setores públicos; e, por outro lado, uma tendência política diversificada a respeito da apropriação e dos usos possíveis das águas minerais, inclusive reconhecendo e valorizando suas propriedades terapêuticas como elemento não humano extraordinário. Ao entender que o controle da água é o controle político do território (PORTO-GONÇALVES, 2012), questiona-se: quem controla a água em Caxambu?

Em termos metodológicos, apresentam-se aqui as discussões oriundas de dados de pesquisa de campo desenvolvida em Caxambu, referentes à observação participante em fóruns regionais, audiências e manifestações públicas; e de entrevistas com moradores e visitas ao Parque das Águas, realizadas entre 2017 e 2018.

O artigo está organizado em cinco tópicos. No primeiro, apresenta-se uma breve discussão acerca das regulamentações sobre recursos hídricos e minerais no Brasil, especificamente no que tange às águas minerais, apresenta dualidades 
em relação à sua interpretação legal. Em seguida, expõe-se os aspectos históricos e cosmológicos das águas minerais em Caxambu. No terceiro tópico, discute-se a perspectiva construída neste trabalho, sobre as diferentes vertentes de uso das águas no município; e no quarto, debate-se o conflito ambiental propriamente dito. Ao final, são feitas ainda algumas considerações sobre a pesquisa realizada.

\section{1 ÁGUAS MINERAIS: RECURSO HÍDRICO OU MINERAL?}

A água é um recurso vital, que deve ser adequadamente utilizado e preservado, cabendo ao Direito, por meio de leis, decretos etc.; definir as atividades a serem regulamentadas para garantir o atendimento das demandas da sociedade. A criação do Direito das Águas, aqui entendido como um conjunto de processos legiferantes em diferentes países, é um dos instrumentos para regulamentar o uso das águas. No Brasil, ele é representado principalmente pelo Decreto no 24.643/34 (BRASIL, 1934 - Código das Águas) e pela Lei nº 9.433 de 1997 (BRASIL, 1997), que trata da Política Nacional de Recursos Hídricos e que criou o Sistema Nacional de Gerenciamento de Recursos Hídricos (CAUBET, 2009).

Serra (2009), ao abordar a questão histórica da institucionalidade das águas no Brasil, afirmou que, inicialmente, o entendimento legal em relação às águas seguiu leis voltadas à gestão hídrica. Inclusive, o autor argumentou que as primeiras leis sobre propriedade mineral excluíam do conceito de minas as fontes de águas minerais.

Entretanto, atualmente, as águas minerais não estão sujeitas às leis referentes à gestão hídrica, e são consideradas recursos minerais pelo Código de Mineração (BRASIL, 1967). Ora, mas se as águas minerais são parte do ciclo hidrológico, por que elas são excluídas de uma política de recursos hídricos ou mesmo de um Código das Águas?

Compreende-se que o Código de Mineração, posterior ao Código das Águas e anterior à Política Nacional de Recursos Hídricos, contribuiu para essa imprecisão conceitual quando definiu que os recursos minerais são formados por substâncias minerais ou fósseis, sem, contudo, demarcar quais substâncias formariam quais minerais. Então, como delimitar o que é um recurso mineral sem a conceituação das substâncias que o formam?

O Decreto nำ 62.934/68 (BRASIL, 1968) aprovou o Regulamento do Código de Mineração, especificando oito classes relacionadas às jazidas minerais, 
sendo a oitava, as águas minerais. O mesmo decreto, todavia, indicou que é a partir da Mineralogia que se é possível determinar o que é um mineral.

Teixeira et al. (2000) delimitaram conceitualmente um mineral como sendo uma substância de ocorrência natural, sólida, cristalina, inorgânica e de específica composição química. Os autores indicaram também que minerais são homogêneos e não podem ser divididos em componentes menores. Press et al. (2006), por sua vez, argumentaram que minerais são elementos ou compostos químicos cristalizados, formados por meio de processos geológicos inorgânicos. Por fim, ao diferenciar mineral e minério, essa literatura indicou ainda que este último é definido por aqueles minerais com valor econômico no mercado.

Essa literatura básica indicou, portanto, que minerais não são líquidos ou gases (com exceção do mercúrio). Mas a dúvida permanece: se a água não poderia ser um mineral, seria ela um minério? O argumento jurídico utilizado é o de que a água considerada mineral é caracterizada como uma associação de minerais com valor econômico e que, assim, poderia ser considerada um minério; isso porque a composição química da água mineral é delimitada por meio de análises dos teores de sais minerais como magnésio, potássio, bicarbonato e sódio.

Isso resolveria um problema de imprecisão conceitual a partir de determinado arcabouço jurídico e técnico-científico, mas logo apresenta outro de ordem política: se as águas minerais, consideradas águas subterrâneas, fazem parte de um ciclo hidrológico, quem faz sua gestão?

A Constituição Federal (CF) definiu como bens do Estado, "as águas superficiais ou subterrâneas, fluentes, emergentes e em depósito, ressalvadas, neste caso, na forma da lei, as decorrentes de obras da União" (BRASIL, 1988, não paginado). Porém, a Lei n⿳0 9.433/97, ao enfocar especificamente as águas subterrâneas, mencionou que estas estão sujeitas a regime jurídico diferenciado, em especial aquele vinculado às águas minerais, que são tratadas como recursos minerais e não como recursos hídricos. Neste caso, a CF esclareceu que "os recursos minerais, inclusive os do subsolo, são considerados bens da União" (BRASIL, 1988, s/n), indicando, assim, que os recursos minerais constituem propriedade distinta do solo para efeito de exploração, garantindo a um concessionário o produto da lavra (CAUBET, 2009).

No caso da exploração de águas minerais, o Código de Mineração, em seu art. 10, informou que estas jazidas devem obedecer legislação especial para serem exploradas, particularmente o Decreto-Lei n⿳⺈ 7.841/45 denominado Código das Águas Minerais, que estabeleceu, no seu Art. 1ํ, que: 
Águas minerais são aquelas provenientes de fontes naturais ou de fontes artificialmente captadas que possuam composição química ou propriedades físicas ou físico-químicas distintas das águas comuns, com características que lhes confiram uma ação medicamentosa (BRASIL, 1945, não paginado).

Conforme Caubet (2009), no entanto, é complicado dizer, tal como o Decreto-Lei $\mathrm{n}^{\circ} 7.841 / 45$ sugeriu, quais seriam as características distintas das águas que fariam com que elas fossem consideradas minerais, já que toda água subterrânea tem certo conteúdo de sais minerais devido ao processo de mineralização que ocorre quando do contato com rochas e solos. Isso leva esse autor a concluir que, em maior ou menor grau, toda a água subterrânea poderia ser explorada comercialmente como água mineral, demonstrando incoerência legal no tratamento da matéria.

Essa breve discussão leva a argumentar que as águas minerais, que são águas subterrâneas, enquanto recurso mineral, estão sujeitas às leis e decretos relativos à mineração, porém, enquanto recurso hídrico e parte do ciclo hidrológico, elas também estariam sujeitas às normas ambientais, em especial as que disciplinam o uso dos recursos hídricos (CAUBET, 2009). Importa salientar que tal dualidade demostra uma série de divergências na gestão dos recursos hídricos no Brasil em função de existir dois instrumentos institucionais distintos e não complementares.

Esse argumento não é bem uma novidade, já que, conforme indicou Scalon (2011) e Portugal Júnior (2016), foi aprovada no Conselho Nacional de Recursos Hídricos a Resolução n⿳⺈ 76/07. Tal resolução, em teoria, propiciaria aos órgãos gestores o conhecimento das outorgas de recursos minerais e das outorgas de direitos de uso dos recursos hídricos. Na prática, porém, a gestão conjunta ainda não ocorre, o que tem agravado teses conflitantes (e conflitos!) no que tange à gestão de águas minerais no Brasil.

\section{ASPECTOS HISTÓRICOS E COSMOLÓGICOS DAS ÁGUAS MINERAIS EM CAXAMBU}

Uma análise histórica acerca dos significados das águas minerais no sul de Minas Gerais ajuda a reconhecer e justificar a importância desse recurso em contextos socioculturais conflitantes. Numa conceituação objetiva, o Sumário Mineral (BRASIL, 2014) definiu que água mineral é obtida diretamente de fontes 
naturais ou por extração subterrânea e que ela se caracteriza pelo conteúdo de sais minerais constituintes. Os sais minerais contidos nas águas de Caxambu dão a elas um poder curativo a muitas enfermidades, o que deu origem à prática de seu uso terapêutico.

Segundo Valadão et al. (2018), o uso terapêutico das águas minerais antecede a chegada dos colonizadores portugueses ao Brasil. No caso do Circuito das Águas, os autores destacaram que os indígenas Puris tinham uma relação sagrada com a natureza, em especial com as águas minerais, marcando o território do sul de Minas como um espaço sagrado. Segundo eles:

No sentido afetivo, pode-se dizer que a região era de terras sagradas e de reverência, verdadeiras farmácias naturais nas quais se buscava a cura física e espiritual - o que posteriormente foi condensado pelo saber médico-científico sob a nomenclatura de crenoterapia (VALADÃO et al., 2018, p. 26).

No processo de colonização do Brasil, os povos originários "foram expulsos, mortos, escravizados ou catequizados" (VALADÃO et al., 2018, p. 27), fazendo com que parte da identidade e história relacionada às águas da região também fossem suprimidas. Em Caxambu, por exemplo, a data de 1748 é significativa, com a construção de uma capela homenageando N. Sra. dos Remédios (RESENDE, 2015), uma santa católica de origem portuguesa, indicando a forte influência religiosa na região, o reconhecimento do poder das águas e a supressão das culturas indígenas.

No século XIX, a informação sobre os poderes curativos das águas minerais em Caxambu se expandiu, em especial com o advento da visita da família imperial. Segundo Souza (2014), em 1868 tal visita levou ao conhecimento da corte portuguesa informações sobre os efeitos curativos e terapêuticos das águas de Caxambu. Em sequência, quatro das doze fontes do Parque das Águas, criado em 1841 (RESENDE, 2015), foram batizadas com o nome de membros da família imperial.

A partir daí, no início do século XX, a emancipação político-administrativa de Caxambu aumentou os investimentos em infraestrutura e serviços. A posição equidistante do Rio de Janeiro e de São Paulo, atrelada às atividades de cassino, movimentaram grande número de curiosos de todo Brasil sobre o poder curativo das águas minerais do município (JUNQUEIRA, 2018).

Esse processo sugere, portanto, que ocorreram mudanças de valores sobre os usos e apropriação das águas minerais por diferentes grupos sociais 
em Caxambu. Isto é, que as águas foram perdendo o seu sentido identitário relacionado à cultura indígena e passaram a ter um sentido mais privatista de saúde e acesso para posterior valorização econômica, deixando em segundo plano até seus poderes curativos e, principalmente, sua relevância cultural (VALADÃO et al. 2018). Tais inferências levaram à interpretação dos papéis que as águas em Caxambu desempenham na atualidade, neste trabalho entendido como "vertentes" das águas minerais.

\section{VERTENTES DAS ÁGUAS MINERAIS EM CAXAMBU}

Nesse tópico, desvela-se como o sentido das águas minerais em Caxambu sofreu modificações ao longo do tempo e argumenta-se que, no período recente, a tendência privatista das águas minerais observada no contexto mundial (RIBEIRO, 2009; PORTO-GONÇALVES, 2012) também tem ganhado força nesse município.

\section{4 ÁGUA MINERAL COMO SAÚDE E DIREITO}

Inicialmente, ao se tomar as perspectivas apresentadas sobre os usos históricos das águas minerais nesse município, pôde-se refletir sobre seus usos terapêuticos, sob o espectro de uma medicina popular (RODRIGUES, 2001), às vezes associada a aspectos da espiritualidade. A partir da literatura, percebeuse uma relação entre cura, promovida pelas águas, junto a orações e prática espiritual, reflexo da cultura dos povos originários mesclada com elementos da religião católica (SOUZA, 2014; RESENDE, 2015; VALADÃO, et al., 2018)

Como parte desse saber difuso da medicina popular, ainda nos dias de hoje, é possível ouvir em toda a cidade de Caxambu pessoas indicando águas das mais variadas fontes para auxiliar no tratamento de diversos problemas de saúde. Expressões como "a água da Mayrink é boa para a garganta", "Está com anemia? Tome a água da D. Isabel e Conde D’Eu!” ou, ainda, “A água da Dom Pedro é boa para o estômago". Entende-se que isso se trata de uma idiossincrasia só encontrada nessas áreas.

O reconhecimento das propriedades terapêuticas e curativas das águas minerais se manteve vivo entre os moradores locais, tal como o trecho de uma entrevista realizada mostra: 
O gêiser jorra todos os dias às 10:30h da manhã. A água sai quentinha, faz bem para a pele, faz bem para tudo. Não aparento ter a idade que tenho porque tomo banho de gêiser todos os dias (Morador local e frequentador do Parque das Águas, entrevista realizada durante trabalho de campo em 2018).

No período recente também é possível delimitar esse conhecimento sobre as propriedades físico-químicas das águas de Caxambu a partir da sistematização de um conhecimento cientificamente reconhecido. Atualmente, cada fonte do Parque das Águas possui uma placa informativa sobre os componentes minerais encontrados nas respectivas águas e para quais problemas de saúde elas são indicadas - medicamentos das vias digestivas, doenças hepáticas, alergias e afecções cutâneas, calmante do sistema nervoso, dentre outros (LEMOS, 1998; CATALAN, 2010).

Dada a importância e as características preventivas e curativas das águas minerais de Caxambu, sejam as reconhecidas pelo saber popular, sejam as comprovadas por estudos científicos, elas se inserem no âmbito das práticas integrativas de saúde: um conjunto de práticas que podem ser consideradas alternativas ou complementares às práticas da medicina convencional e como direito humano básico da população.

Nesse contexto, a Organização Mundial da Saúde (OMS), "estimula, desde o final da década de 1970, a implantação da chamada Medicina Tradicional ou Medicina Complementar e Alternativa nos Sistemas de Saúde" (SOUSA et al., 2012, p. 2143). Nos anos de 2002 e de 2003 foram publicados documentos e resoluções, como o Estratégia da OMS sobre Medicina Tradicional 2002-2005, com orientações que preconizam a implantação dessas práticas integrativas como ações institucionais, reconhecidas na forma da lei, as quais incluem-se quatro pilares: 1) estruturação de política; 2) garantia de segurança da qualidade da água; 3) garantia de eficácia; 4) ampliação do acesso; e 5) o uso racional (BRASIL, 2006).

No Brasil, uma via encontrada para a consolidação da política de práticas integrativas foi a sua integração ao Sistema Único de Saúde (SUS). Sob as diretrizes da OMS, a Política Nacional de Práticas Integrativas e Complementares em Saúde (PNPIC) foi sancionada em 2006, possibilitando o uso de práticas alternativas, integrativas e complementares no SUS, entre as quais se destacam o termalismo/ crenoterapia (BRASIL, 2006). Além de trazer consigo um resgate e valorização de costumes e culturas ancestrais, a PNPIC contribui para o fortalecimento dos princípios fundamentais do sistema de saúde público. 
Portanto, ao se analisar o acesso às águas minerais em Caxambu a partir do viés da saúde, deve-se trazer essa discussão para dentro da esfera pública de direitos, já que o que garantiu a institucionalização das práticas integrativas no Brasil foi o diálogo de saberes da medicina convencional com a medicina popular, constituindo-se como um meio de interlocução constante entre as esferas de governo e a sociedade civil (BRASIL, 2006).

No entanto, curiosamente, percebe-se que não há aplicação da PNPIC em Caxambu. Em fóruns, audiências e encontros sobre o tema, essa possibilidade é abordada de forma tímida e, quando citada, é mencionada apenas como um objetivo, não tratando os caminhos para a sua consecução. O relato a seguir, feito por ocasião do I Fórum das Águas Minerais do Circuito das Águas do Sul de Minas, mostra isso muito bem:

Estive presente no $8^{\circ}$ Fórum Mundial da Água, realizado em Março [2018], na cidade de Brasília e as águas minerais não foram citadas em nenhum momento. Elas não são reconhecidas (Pesquisador, durante o I Fórum das Águas Minerais, realizado em Cambuquira-MG, em 14 de abril de 2018).

Quais seriam as possíveis razões para isso? A hipótese que melhor parece se constituir empiricamente é a de que há um conflito de interesses explícito: água como saúde e direito humano versus água como mercadoria.

\section{5 ÁGUA MINERAL COMO MERCADORIA}

Nos marcos das sociedades capitalistas e de cunho neoliberal, considerar a água como bem público e controlado pelo Estado alude a uma gestão ineficaz. Sob esta lógica a água deveria ser privatizada para que os mecanismos de mercado operassem na sua gestão. O pressuposto para isso seria o de que a água deve ser tratada como um bem econômico (PORTUGAL JÚNIOR, 2016).

Acontece que esses são justamente os ingredientes principais de um processo de privatização, ou, como é aludido em algumas propostas internacionais, de "gestão integrada dos recursos hídricos" (Integrated Water Resources Management), conceito chave de políticas a serem praticadas em diferentes escalas e territórios. A privatização, assim, colocar-se-ia como um conjunto de serviços que visariam assegurar e gerir racionalmente um recurso natural por meio de sua remuneração (PORTO-GONÇALVES, 2012). 
Por possuir aspectos ligados à saúde, as águas de Caxambu possuem um grande poder mercadológico. Além disso, em grandes centros urbanos muitas pessoas costumam comprar a água "gourmet" de Caxambu para atender suas mais altas necessidades de diferenciação social ou mesmo por, de alguma forma, acreditarem em suas propriedades medicamentosas. Segundo Rebouças (2004, p. 122), o mercado de água engarrafada no Brasil é controlado por grupos de interesse que rotulam a água "potável de mesa" como água mineral, possibilitando concorrer no mercado internacional. Essa água mineral "gourmet" pressupõe a elitização do produto, tornando-se, cada vez mais, símbolo de status social e consolidando-se como forma de mercantilizar e precificar a água (MOURA et al., 2011).

A esse fenômeno se une a polêmica já apresentada em tópico anterior, sobre a classificação das águas minerais e sua consideração enquanto minério, endossando o caráter puramente econômico que a água mineral pode ter. Tal fato vai de encontro aos mais diversos significados e à importância que as águas minerais têm para os habitantes das diversas estâncias hidrominerais espalhadas pelo país, que vão muito além do viés financeiro; haja vista que as principais funções das águas minerais estão atreladas à "identidade das localidades, à sua organização, às atividades produtivas, à geração de empregos, à difusão de tecnologia e à defesa do meio ambiente" (NINIS; DRUMMOND, 2008, p. 150). Isto posto, em relação às falhas na gestão das águas minerais, as estâncias hidrominerais têm sofrido impactos negativos, tais como a perda das características físico-químicas de suas águas, perda de seus papéis identitários, prejuízos para os serviços ligados ao turismo e enfraquecimento das relações comunitárias construídas em torno das águas (NINIS; DRUMMOND, 2008).

E é neste contexto caracterizado por contradições jurídicas, interesses econômicos e possibilidades políticas diversas que se dá o conflito ambiental em Caxambu. O potencial hidromineral desse município passa por um momento importante de sua história em que diferentes significações dadas às águas minerais ocasionam conflitos que mostram que se deve optar por um caminho que seja interessante para a sociedade e para o poder público.

\section{AS VERTENTES DAS ÁGUAS E O CONFLITO AMBIENTAL EM CAXAMBU}

Ao discutir a natureza dos conflitos ambientais, baseado fundamentalmente nos diferentes usos e apropriações do espaço geográfico, Acselrad (2004, p. 
26) argumentou que o espaço é um recurso comum, porém exposto a distintos projetos e formas de apropriação material e simbólica. Nesse sentido, os conflitos ambientais são entendidos por esse autor como "aqueles envolvendo grupos com modos diferenciados de apropriação, uso e significação do território" e que têm origem quando "pelo menos um dos grupos tem a continuidade das formas sociais de apropriação do meio que desenvolvem ameaçadas por impactos indesejáveis [...] decorrentes do exercício das práticas de outros grupos" (ACSELRAD, 2004, p. 26).

Tendo essa argumentação como pressuposto, entende-se que os diversos interesses sobre o uso e a gestão das águas minerais em Caxambu podem ser indicados como um conflito ambiental, uma vez que, ao longo do tempo, a gestão do Parque das Águas nesse município e a exploração das águas minerais (envasamento) sofreu mudanças de gestão e de concessão, causando insatisfação na população que usa esse recurso de forma tradicional e para fins terapêuticos.

Atualmente a gestão do Parque das Águas pertence ao governo de Minas Gerais. Porém, de 1989 a 2017, ele foi administrado pela prefeitura municipal, por meio de um contrato de Cessão de Direito de Uso de Imóvel. A partir de 1 de outubro de 2017, este contrato chegou ao fim, e diante da impossibilidade de renová-lo, por conta de um suposto déficit, o parque voltou a ser gerido pelo governo estadual, via Companhia de Desenvolvimento de Minas Gerais (CODEMIG). Ao reassumir a gestão do Parque das Águas em Caxambu, a empresa emitiu a seguinte nota:

A Codemig esclarece que não há qualquer intenção de fechamento do Parque das Águas. Pelo contrário, a Empresa reconhece sua relevância para além das esferas local e regional, tratando-o como rico e diversificado patrimônio, ao qual dedica especial atenção. Nessa perspectiva, a Codemig atua de modo a sempre valorizar e cuidar da preservação desse e de outros importantes acervos turísticos e históricos de Minas Gerais. Contudo, de acordo com dados apresentados pela Prefeitura Municipal de Caxambu, o resultado financeiro do Parque das Águas da cidade é historicamente deficitário: o resultado de 2013 a 2016 aponta déficit acumulado de $\mathrm{R} \$$ 1.089.695,64 (CODEMIG, 2017a, não paginado).

Acontece que o parque atualmente pertence ao governo de Minas Gerais, porém, o envasamento já foi de responsabilidade da iniciativa privada em diversas ocasiões. Assim, nas últimas duas décadas, a exploração das águas minerais, então, tem migrado entre a iniciativa privada e o poder público, causando diferenciações e mudanças de sentido e uso. 
A Hidrominas, empresa pública do estado de Minas, era a responsável pelo envasamento das águas na década de 1970. A partir de 1981, a empresa Superágua, do grupo Supergasbrás, passou a comandar o ramo. Essa parceria durou até 2005. Em 2006, porém, a exploração das águas voltou para o poder público. Entretanto, no mesmo ano a CODEMIG arrendou para a Companhia de Saneamento de Minas Gerais (COPASA) o direito de exploração das águas do município, que o fez por meio de sua subsidiária: Águas Minerais de Minas (AGMM).

Em 2015, o contrato da CODEMIG com a AGMM foi reformulado, e ela passou a operar os complexos fabris de envasamento de água como prestadora de serviços ao governo do estado. Isso durou até abril de 2016. A partir de maio deste mesmo ano, a própria CODEMIG, por meio de sua subsidiária CODEÁGUAS, assumiu, então, o engarrafamento. Entre maio de 2016 e janeiro de 2017, a CODEMIG diz ter acumulado um prejuízo de R\$ 1.659.901,36 (CODEMIG, 2017b, p. 21). Diante desse cenário, foi aberto, novamente, processo licitatório

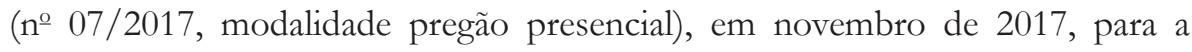
consecução de uma parceria público-privada para o ramo de engarrafamento de águas em Caxambu.

O edital desse processo licitatório foi amplamente criticado pela população caxambuense, pois não trazia em seu texto um número máximo de litros a serem explorados pela empresa e, assim, tinha um cunho nem um pouco sustentável. Dessa maneira, em entrevista ao site do jornal "O Beltrano", uma advogada e representante das organizações Caxambu Mais e Ampara, relata:

Quando foi realizada a consulta pública, a sociedade civil organizada, os moradores da região e o Ministério Público manifestaram-se contrários à proposta apresentada pela Codemig. Nem mesmo as nossas contribuições foram acatadas. O edital não obriga a empresa a usar as marcas Caxambu e Cambuquira, por exemplo. Foi desconsiderado todo o patrimônio histórico e o processo democrático (MACIEL, s. d., não paginado).

No que diz respeito ao engarrafamento, exigia-se das concorrentes apenas a capacidade de comercializar, no mínimo, 12 milhões de litros por ano. Além disso, houve muita controvérsia e desconfiança acerca da empresa vencedora do pregão, a Maximus Prestação de Serviços, que venceu a licitação em dezembro de 2017 e assumiu o engarrafamento em abril de 2018. Acontece que essa empresa não tem experiência no ramo de águas minerais e seu capital social para adequação ao edital subiu exponencialmente num curto período de tempo, como mostra o trecho transcrito a seguir: 
a empresa Máximus Prestação de Serviços tem entre suas atividades registradas a prestação de serviços de construção e também limpeza de caixas de água e de gordura, faxina de prédios, dedetização, tratamento de piscinas, entre outras, mas nunca lidou com produção ou distribuição de água mineral (DOC Maximus). Trata-se, na verdade, de uma pequena empresa de prestação de serviços para condomínios. Até duas semanas antes da licitação, a Máximus era uma empresa de capital social quase que irrisório. Para se adequar ao edital, no entanto, seu capital foi integralizado e aumentado em 1.500\%, saltando de R \$ 100 mil para R \$ 1,5 milhão (Capital Social Maximus). Quem representou a Máximus no processo licitatório foi o empresário Elton Sales (ele não é o dono da empresa, mas foi quem assinou por ela) (Elton Sales). Sales, na verdade, é dono da empresa Embraser Serviços, que está impedida, desde maio de 2015 até maio de 2018, de prestar serviços ao governo de Minas por descumprimento de obrigações em contratos anteriores (MACIEL, s.d., não paginado, grifos no original).

É nesse contexto de mudanças constantes na gestão do Parque das Águas e na exploração das águas minerais de Caxambu, aliado aos tradicionais usos terapêuticos das águas e apropriações públicas desse bem natural, que emerge o conflito ambiental. Todos os acontecimentos recentes mencionados nos diferentes tópicos do trabalho geraram um tensionamento entre população caxambuense, CODEMIG e empresa Maximus. Visto que o momento é de mais uma transição na gestão e envasamento das águas do Parque das Águas de Caxambu, algumas reuniões, audiências e palestras foram realizadas, a fim debater os problemas, as potencialidades e um modelo de gestão social e compartilhado.

O fato é que o sentido econômico da água mineral tem tido mais relevância e interesse nas esferas públicas de debates do que os outros sentidos que ela traz intrinsecamente, seja enquanto direito humano básico, seja enquanto terapia. O principal deles, que se opõe veementemente ao viés econômico, é o seu sentido ambiental, de sustentabilidade.

É possível notar a valorização do viés econômico de apropriação das águas minerais de Caxambu nos discursos da CODEMIG, indicando um posicionamento estatal acerca do tema e da questionável parceria público-privada realizada para o engarrafamento das águas minerais do Parque das Águas de Caxambu.

A iniciativa do Governo estadual é importante para viabilizar os negócios e potencializar seu dinamismo, além de ampliar o público-alvo das águas minerais [...] A Codemig procura, assim, maximizar o retorno econômico para o Estado e a sociedade, considerando sempre a gestão eficiente dos recursos públicos. Além disso, a Empresa objetiva fomentar novos modelos de negócio e ampliar as vantagens competitivas do nosso estado [...] A atuação da Empresa segue voltada para que riquezas e potencialidades gerem novas oportunidades de investimentos, aumentem a competitividade e propiciem bons negócios para a economia mineira (CODEMIG, 2017b, não paginado). 
Nesta senda, o exemplo de São Lourenço, que também faz parte do Circuito das Águas sul mineiro, serve de alerta. A Nestlé Waters, multinacional suíça, geriu o Parque das Águas desse município entre 1992 e 2018, por meio de um processo de privatização. Foi um período marcado por intensos conflitos ambientais, tal como registrado por Carneiro e Assis (2013). No final da década de 1990, a Nestlé realizou uma ampliação do seu pátio no Parque das Águas e, nesse período, foram notados afundamentos do solo e rachaduras nas construções, interrupções e redução da vazão espontânea de algumas fontes, alterações no sabor de algumas águas e a demolição da fonte Oriente para que fosse adaptada às ampliações da empresa (VIANNA, 2018).

Portanto, entende-se que, assim como a água enquanto "recurso econômico" é digna de nota devido à sua evidência em todo o processo do conflito, a "água como saúde e direito”, por sua omissão no debate, também o é. É importante enfatizar que a utilização da água mineral para fins terapêuticos de amplo acesso à população não impossibilita o seu uso comercial. A difusão do poder terapêutico das águas minerais pode impulsionar o chamado "turismo de saúde", como já aconteceu na história de Caxambu.

Assim, não é impensável imaginar uma proporcionalidade entre os diferentes interesses envoltos nas águas minerais de Caxambu. Baseandose na simetria e no equilíbrio, e das prioridades - direito e saúde - é possível uma exploração sustentável das águas de Caxambu, de modo que as práticas terapêuticas, amparadas pela PNPIC, não sejam ignoradas e coexistam com o “negócio das águas"; respeitando o Direito Humano à água preconizado pela ONU (2010) e preservando a existência de um recurso comprovadamente raro e resgatando, valorizando e conservando a história e a cultura do povo. Nesse processo, como nos mostrou Vianna (2018), a discussão da água mineral como recurso hídrico ou mineral é, por um momento, esgotada, e é possível considerála um recurso híbrido.

O conflito ambiental em Caxambu traz em si, portanto, os diferentes significados territoriais "em jogo" nos usos e apropriações das águas minerais nesse município, mas, também, tem a ver com incongruências legais no tratamento dos usos dos recursos hídricos e minerais no Brasil. Argumenta-se que, para que sejam tomadas providências em relação a essa seara, para além da gestão territorial, há que se ter em mente a necessidade de modificações regulatórias em relação aos recursos hídricos e minerais no Brasil, de modo que haja complementariedade em lugar de conflito na legislação. 


\section{CONSIDERAÇÕES FINAIS}

Analisaram-se os sentidos e a importância das águas minerais no Circuito das Águas de Minas Gerais, mais precisamente em Caxambu, bem como refletiu sobre possibilidades de utilização das águas a partir de instrumentais políticos e jurídicos.

Nesse processo, evidenciaram-se as distinções jurídicas envolvidas na conceituação e na regulação das águas minerais no Brasil. Compreendeu-se, portanto, que tal fato ocorreu em virtude de alterações na interpretação do Código das Águas Minerais, encabeçadas pelo Código da Mineração, permitindo a classificação de praticamente todo tipo de água subterrânea potável como água mineral.

No caso em tela, nota-se que os conflitos acerca das águas minerais em Caxambu são de longa data, embora eles tenham sido visibilizados a partir da privatização efetiva da exploração das águas minerais em anos recentes. $\mathrm{O}$ motivo principal desses conflitos é justamente os diferentes sentidos que a água possui para distintos grupos sociais. Desse modo, para pesquisas posteriores, resta-nos saber em que medida a integração de informações sobre gestão das águas minerais no Brasil, propostas na Resolução n⿳0 076/2007 (BRASIL, 2007) do Conselho Nacional de Recursos Hídricos, possibilita a redução dos conflitos ambientais em municípios que possuem "águas medicamentosas".

Analisaram-se, também, as diferentes vertentes de significação das águas minerais em Caxambu: a água como saúde e direito; e a água como mercadoria. A primeira resgatou o uso da água mineral como tratamento terapêutico e a possibilidade de utilização da crenoterapia e do termalismo social alicerçado na PNPIC, tratando-a também como direito humano básico. A outra vertente, por sua vez, diz respeito aos aspectos puramente econômicos e mercadológicos das águas minerais e que desafiam o sentido da água como direito de todos e a sua gestão de forma sustentável.

Essas diferentes vertentes de significação das águas minerais em Caxambu nos conduziram a analisar, neste artigo, o conflito ambiental nesse município pautado no embate entre CODEMIG/CODEMGE, iniciativa privada e sociedade civil, seja por sua explicitação ou por sua omissão. Aliás, considerando a existência da PNPIC, a irrelevância com a qual o tema é debatido causa certo estranhamento, haja vista que a sua utilização é pouco onerosa ao poder público e resgata aspectos culturais e terapêuticos das águas minerais.

Ao final, o caso de São Lourenço foi evocado como alerta oportuno à população de Caxambu, dado que o processo de privatização no município citado impactou fortemente o parque e suas águas minerais, tanto no viés estrutural 
das fontes, quanto no viés qualitativo das águas, o que gerou conflitos entre a sociedade civil e a Nestlé Waters, empresa que fazia a gestão do Parque das Águas desse município à época.

Ademais, como aborda o artigo, a água possui diversas significações. Embasando-se em Latour (1994) e Vianna (2018, p. 74), é possível perceber a presença "dos híbridos de tempos (o velho e o novo), de escalas (global e local), de saberes (científico e "popular") e de políticas e interesses (público e privado)" que se constituem em um universo a ser pesquisado.

\section{REFERÊNCIAS}

ACSELRAD, H. As práticas espaciais e o campo dos conflitos ambientais. In: ACSELRAD, H. (Org.) Conflitos ambientais no Brasil. Rio de Janeiro: Relume Dumará: Fundação Heinrich Böll, 2004. p. 13-35.

BRASIL. Decreto n 24.643 , de 10 de julho de 1934. Código de Águas. Diário Oficial da União. Brasília-DF, 20 de jul. 1934. Disponível em: http://www.planalto.gov.br/ ccivil_03/decreto/D24643.htm. Acesso em: 15 nov. 2018.

BRASIL. Decreto-Lei no 7.841 de 8 de agosto de 1945, Código das Águas Minerais. Diário Oficial da União. Brasília-DF, 20 ago. 1945. Disponível em: http://www.planalto.gov. br/ccivil_03/decreto-lei/1937-1946/Del7841.htm. Acesso em: 15 nov. 2018.

BRASIL. Decreto no 62.934 de 02 de julho de 1968, Aprova o Regulamento do Código da Mineração. Diário Oficial da União. Brasília-DF, 5 jul. 1968. Disponível em: http:// www.planalto.gov.br/ccivil_03/decreto/1950-1969/d62934.htm. Acesso em: 15 nov. 2018. BRASIL. Decreto-Lei no 227 de 28 de fevereiro de 1967, Código da Mineração. Diário Oficial da União. Brasília-DF, 28 fev. 1967. Disponível em: http://www.planalto.gov. br/ccivil_03/Decreto-Lei/Del0227.htm. Acesso em: 15 nov. 2018.

BRASIL. Constituição (1988). Constituição da República Federativa do Brasil. BrasilliaDF: Senado Federal, Centro Gráfico, 1988. Disponível em: http://www.planalto.gov.br/ ccivil_03/Constituicao/Constituicao.htm. Acesso em: 15 nov. 2018.

BRASIL. Lei no 9.433, de 8 de janeiro de 1997, institui a Política Nacional de Recursos Hídricos, cria o Sistema Nacional de Gerenciamento de Recursos Hídricos, regulamenta o inciso XIX do art. 21 da Constituição Federal, e altera o art. $1^{\circ}$ da Lei no 8.001, de 13 de março de 1990, que modificou a Lei n 7.990 , de 28 de dezembro de 1989. Diário Oficial da União. Brasília-DF, 09 jan. 1997. Disponível em: http://www.planalto.gov.br/ccivil_03/ LEIS/L9433.htm. Acesso em: 15 nov. 2018.

BRASIL. Portaria $\mathbf{n}^{\circ} \mathbf{9 7 1}$, de 3 de maio de 2006. Aprova a Política Nacional de Práticas Integrativas e Complementares (PNPIC) no Sistema Único de Saúde (SUS). Brasília: Ministério da Saúde, 2006.

BRASIL. Resolução No76, de 16 de outubro de 2007, Estabelece diretrizes gerais para a integração entre a gestão de recursos hídricos e a gestão de águas minerais, termais, gasosas, 
potáveis de mesa ou destinadas a fins balneários. Diário Oficial da União. Brasília-DF, 27 nov. 2007. Disponível em: http://www.cnrh.gov.br/aguas-subterraneas/17-resolucaon-76-de-16-de-outubro-de-2007/file. Acesso em: 15 no. 2018.

BRASIL. Ministério de Minas e Energia. Departamento Nacional de Produção Mineral. Sumário Mineral, Brasília: Ministério de Minas e Energia, 2014. Disponível em: http:// www.dnpm.gov.br/dnpm/sumarios/sumario-mineral-2014. Acesso em: 28 jul. 2018.

CARNEIRO, E. J.; ASSIS, M. F. da C. Conflitos ambientais em Minas Gerais: a exploração da água na microrregião de São Lourenço. Estudos Sociales, Bogotá, p. 1029, jan./jun. 2013. Disponível em: http://www.scielo.org.mx/scielo.php?pid=S018845572013000100001\&script=sci_arttext\&tlng=en. Acesso em: 15 nov. 2018.

CATALAN, R. Parque das Águas. [2010]. Disponível em: http:/ /www.descubracaxambu. com.br/parquedasaguas/. Acesso em: 19 jul. 2018.

CAUBET, C. G. Os contextos normativos brasileiros em matéria de águas subterrâneas. In: RIBEIRO, W. C. (Org.). Governança da água no Brasil: uma visão interdisciplinar. São Paulo: Annblume, 2009. p. 213-237.

CODEMIG. Nota da Codemig - Parque das Águas de Caxambu. Belo Horizonte: CODEMIG, 2017a. Disponível em: http://www.codemig.com.br/nota-da-codemigparque-das-aguas-de-caxambu/. Acesso em: 31 jul. 2018.

CODEMIG. Consulta Pública sobre a Licitação para o Projeto dse Exploração de Águas Minerais 01/2017 - Processo Interno 47/2017. Belo Horizonte: CODEMIG, 2017b. Disponível em: http://www.codemig.com.br/wp-content/uploads/ licitacoes/1489693044-Respostas\%20a\%20consulta \%20publica\%2010-3-17.pdf. Acesso em: 29 nov. 2018.

JUNQUEIRA, M. G. P. Histórico. Prefeitura Municipal de Caxambu, Caxambu, 2018. Disponível em: http://www.caxambu.mg.gov.br/v2/historia/. Acesso em: 30 nov. 2018.

LATOUR, B. Jamais fomos modernos. Rio de Janeiro: Ed. 34, 1994.

LEMOS, M. de L. Fontes e Encantos de Caxambu. Caxambu, 1998.

MACIEL, A. A tortuosa concessão das águas de Caxambu e Cambuquira. O Beltrano, Belo Horizonte, s. d. Disponível em: http://www.obeltrano.com.br/portfolio/tortuosa-concessaodas-aguas-de-caxambu-e-cambuquira/. Acesso em: 31 jul. 2018.

MOURA, L. R. C. et al. O comportamento de compra e a percepção dos atributos da água mineral pelos consumidores. Perspectiva, Erechim, v. 35, n. 130, p. 97-112, 2011.

NINIS, A. B.; DRUMMOND, J. A. Áreas (des)protegidas do Brasil: as estâncias hidrominerais. Ambiente e Sociedade, Campinas, v. 11, n. 1, p. 149-166, jan./jun. 2008.

ONU. Direito humano à água e ao saneamento: resolução da Assembleia Geral $\mathrm{n}^{\circ}$ 64/292. Nova Iorque: Assembleia Geral, A/RES/64/292, 2010.

PORTO-GONÇALVES, C. W. A globalização da natureza e a natureza da globalização. 3. ed. Rio de Janeiro: Civilização Brasileira, 2012. 
PORTUGAL JUNIOR, P. dos S. A controvérsia sobre as águas: uma proposta de integração institucional e de políticas públicas para o segmento de águas minerais no âmbito da gestão de recursos hídricos. 2016. Tese (Doutorado em Desenvolvimento Econômico) - Programa de Pós-Graduação em Economia, Universidade Estadual de Campinas, Campinas, 2016.

PRESS, F. et al. (Org.). Para entender a terra. 4. ed. Porto Alegre: Bookman, 2006.

REBOUÇAS, A. Uso inteligente da água. São Paulo: Escrituras Editora, 2004. 207p.

RESENDE, M. J. B. de. Escrita pelas Águas. Idas Brasil, Belo Horizonte, 2015. Disponível em: http://idasbrasil.com.br/Caxambu/Historia/viagem/fatos-historicos. Acesso em: 17 jul. 2018.

RIBEIRO, W. C. (Org.). Governança da água no Brasil: uma visão interdisciplinar. São Paulo: Annblume, 2009.

RODRIGUES, A. G. Buscando raízes. Horizontes Antropológicos, Porto Alegre, v. 7, n. 16, p. 131, 2001.

SCALON, M. G. B. Águas minerais e recursos hídricos: uma perspectiva de gestão integrada. Revista de Direito, Estado e Recursos Naturais, Brasília, v. 1, n. 1, p. 131-160, 2011.

SERRA, S. H. Águas minerais do Brasil: uma nova perspectiva jurídica. Campinas: Millennium, 2009.

SOUSA, I. M. C. de et al. Práticas integrativas e complementares: oferta e produção de atendimentos no SUS e em municípios selecionados. Cad. Saúde Pública [online], v. 28, n. 11, p. 2143-2154, 2012. Disponível em: http://dx.doi.org/10.1590/S0102311X2012001100014. Acesso em: 24 ago. 2018.

SOUZA, L. S. de. Parque das Águas de Caxambu - MG: Propriedades físicoquímicas, aspectos hidrominerais e turísticos. 2014. 76 f. Trabalho de Conclusão de Curso (Bacharelado em Geografia). Faculdade de Geografia, Universidade Federal de Alfenas, Alfenas, 2014. Disponível em: https://www.unifal-mg.edu.br/geografia/sites/ default/files /Parque $\% 20$ das $\% 20 \%$ C $3 \% 81$ guas $\% 20$ de $\% 20$ Caxambu. $\% 20-\% 20$ corrigido. pdf. Acesso em: 25 ago. 2018.

TEIXEIRA, W. et al. (Org.) Decifrando a terra. São Paulo: Companhia Editora Nacional, 2000.

VALADÃO, J. de A. D. et al. (Orgs.). Clamor das águas: a busca por nova identidade para as águas minerais no Brasil. Florianópolis: CAXIF/UFSC, 2018. 175 p.

VIANNA, R. Quem controla a água? Mapeamento de controvérsias na Guerra das Águas em São Lourenço (MG). In: MACEDO, J.; FERNANDEZ, V. (Orgs.). Pedra, planta, bicho, gente... coisas: encontros da teoria ator-rede com as ciências ambientais. Rio de Janeiro: Mauad, 2018. p. 59-77. 